\title{
Swarming of bats at underground sites in Britain-implications for conservation
}

\author{
Katharine N. Parsons ${ }^{\mathrm{a}, *}$, Gareth Jones ${ }^{\mathrm{a}}$, Ian Davidson-Watts ${ }^{\mathrm{b}}$, Frank Greenaway ${ }^{\mathrm{c}}$

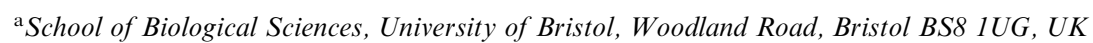 \\ ${ }^{\mathrm{b}}$ English Nature, Northminster House, Peterborough PE1 1UA, UK \\ ${ }^{\mathrm{c}}$ Natural History Museum, Cromwell Road, London SW7 5BD, UK
}

Received 4 February 2002; received in revised form 24 June 2002; accepted 24 June 2002

\begin{abstract}
We investigated the extent of visitation of underground sites during late summer and autumn ('swarming') by bats. Bats were captured at eight cave, mine and tunnel sites in southern England over 6 years (1995-2000). A total of 3077 bats representing 11 of Britain's 16 species was caught. Myotis bats predominated in autumn. At some sites these are rarely seen during winter hibernation counts. Myotis nattereri and M. daubentonii were most common. However, species composition changed seasonally. At one site, $M$. brandtii dominated early in the season and at all sites peak activity of $M$. daubentonii was earlier than in $M$. nattereri. Relatively high numbers of internationally vulnerable species such as $M$. bechsteinii and Barbastella barbastellus were recorded. There was a strong male bias in captures of swarming species. Swarming probably has an important reproductive function, most males are reproductively active at this time and such sites may be important for outbreeding. Due to this and the large number of individuals and species concerned, the conservation of 'swarming sites' is vitally important. Clearly swarming sites merit special consideration in conservation management strategies for cave-dwelling bats.
\end{abstract}

(C) 2002 Elsevier Science Ltd. All rights reserved.

Keywords: Chiroptera; Cave conservation; Swarming; Myotis; Bat diversity

\section{Introduction}

Swarming is defined as "the flights of bats through hibernacula in late summer and early fall" (Fenton, 1969), a period loosely classed as between the beginning of August and the end of October in the Northern Hemisphere (henceforth termed the 'swarming season'). Swarming has been investigated in Microchiroptera from North America (Davis, 1964; Davis and Hitchcock, 1965; Hall and Brenner, 1968; Fenton, 1969; Humphrey and Cope, 1976; Thomas et al., 1979; Schowalter, 1980; Whitaker and Rissler, 1992) and continental Europe (Bauerova and Zima, 1988; Harrje, 1994; Degn et al., 1995; Kreutzschmar and Heinz, 1995; Kugelschafter, 1995; Lubczyk and Nagel, 1995; Trappmann, 1997). However, swarming has, until recently, gone unnoticed and unstudied in Britain. To clarify, the behaviour described here ('autumnal swarming') is different from

\footnotetext{
* Corresponding author.

E-mail address: katie.parsons@bristol.ac.uk (K.N. Parsons).
}

'dawn swarming' at the entrance to roosts that has been described for several species (for example, Cross, 1965; O'Shea, 1980, Shiel and Fairley, 2000).

Internationally, the behaviour is most prevalent among bats in the genus Myotis, but to date has been described for 26 species from seven genera of Microchiroptera, most of which are cave-dwelling for part or all of the annual cycle (Barbour and Davis, 1969; Stebbings, 1988; MacDonald and Tattersall, 2001). Swarming aggregations frequently consist of more than one species, and there is usually a strong male bias (Davis and Hitchcock, 1965; Hall and Brenner, 1968; Humphrey and Cope, 1976; Thomas et al., 1979; Bauerova and Zima, 1988). Most bats arrive after dusk and stay for only a few hours before leaving again, meaning that there are typically few bats present during daytime (Hall and Brenner, 1968; Humphrey and Cope, 1976; Harrje, 1994). Several authors have divided the swarming season into two distinct phases: (1) the 'swarming' phase where bats rarely stay longer than a few hours on one night and (2) the 'arrival' or 'in-flight' phase where bats 
are beginning to enter hibernation, remain at the site during the day and are relatively inactive when compared with the previous phase (Fenton, 1969; Degn et al., 1995). No distinction is made between the two phases here, as they were not found to be readily distinguishable in the literature or in practice.

Capture-mark-recapture surveys have suggested a low rate of return by individual bats to swarming sites within the same year (Davis and Hitchcock, 1965; Harrje, 1994; Whitaker, 1998), hence population turnover is probably very high and the populations using such sites are large. We hypothesize that catchment areas of swarming sites will be on a large scale. Male bats of temperate species are sexually primed during autumn having undergone spermatogenesis during the summer months (Racey, 1982; Racey and Entwistle, 2000).

Social behaviour, comprising calling, chasing and copulating, has been observed (Thomas et al., 1979) during swarming, leading to the widely supported hypothesis that the function of swarming concerns mating. Aggregation of females at a familiar location such as a hibernation site would not only facilitate the location of mates by males that are ordinarily dispersed in the environment (Clutton-Brock and Harvey, 1978), but also aid outbreeding by promoting genetic mixing over a large area (Davis and Hitchcock, 1965). A promiscuous mating system with the absence of (obvious) male display and territory defence, and a predisposition to the use of caves, may determine whether a species swarms. Another hypothesis for the function of swarming concerns information transfer whereby adult females show their young of the year the location of traditional hibernacula (Humphrey and Cope, 1976). Alternatively, all individuals may need to locate and assess the condition of known hibernation sites in advance of the forthcoming winter (Fenton, 1969). Swarming sites may also function as stop-offs on migration pathways between summer and winter regions, or between hibernacula (Whitaker, 1998). These theories are not mutually exclusive.

Sixteen bat species are currently recognised as resident in Britain (MacDonald and Tattersall, 2001). Eight regularly use underground sites for hibernation in winter months. Among these, the British population of $M$. nattereri has been considered of international importance (Stebbings, 1988; Hutson, 1993; MacDonald and Tattersall, 2001) and M. bechsteinii, Barbastella barbastellus and Rhinolophus hipposideros are currently given the IUCN status 'Vulnerable' (Hutson et al., 2001). M. bechsteinii is probably one of Britain's rarest mammals (MacDonald and Tattersall, 2001).

The aims of this paper are: (1) to describe the incidence of swarming at underground sites by bat species in Britain. Prior to this study many underground sites in Britain have been routinely surveyed for hibernating bats during the winter months yet have gone unchecked for the remainder of the year; (2) to describe features including species richness, changes in species composition with time, sex and age ratios with the aim of increasing our understanding of swarming behaviour in general. This study has conservation significance for monitoring, and for describing the distribution of bat species, particularly those at low population densities. Swarming studies also describe the annual use of underground sites by bats and findings have implications for site protection and conservation policies.

\section{Methods}

\subsection{Study sites}

Six former stone and chalk mines and two disused railway tunnels in southern England were chosen as study sites (Fig. 1). Data for Cocking and Drover's tunnels in Sussex (G1 and G2) are pooled as site G because of their close proximity $(3 \mathrm{~km})$. Sites A and B were visited every year from 1995 to 2000 , sites C and D in 2000 only. The remaining sites were visited in three, four or five of the 6 years between 1995 and 2000. All sites are known hibernacula for at least one bat species.

\subsection{Field techniques}

Catches to investigate swarming were carried out between the beginning of August and the middle of November each year. Visits were limited to one per fortnight to minimize disturbance to the bats. Bats were caught using one or two harp-traps $(2.4 \times 1.85 \mathrm{~m}$, Austbat Research Equipment, Melbourne, Australia) and/or one or two mist-nets $(6 \mathrm{~m}$, British Trust for Ornithology) (depending on the location and resources available) placed within the entrances to the mines and tunnels at night. Placement of traps and nets remained consistent at each site. Traps were erected between half an hour before sunset and $2.5 \mathrm{~h}$ after sunset (mean $=1.25 \mathrm{~h}$ after sunset) and remained up for a minimum of $1 \mathrm{~h}$ and a maximum of $8 \mathrm{~h}$ (mean $=3.2 \mathrm{~h}, \mathrm{SE}$ 0.169). At site $\mathrm{C}$ catching commenced early on two occasions in August to capture emerging $R$. ferrumequinum for a radio-tracking project. Infrequent catches using the same methodology were carried out in spring and early summer to provide comparison with the swarming data. All sites were visited either by us and/or local bat groups between one and three times during hibernation (December to February) to count hibernating bats. All activities were carried out under licence from English Nature.

\subsection{Data recorded}

Time of capture, species and sex were recorded for each individual. The bats were aged as adults or juveniles 


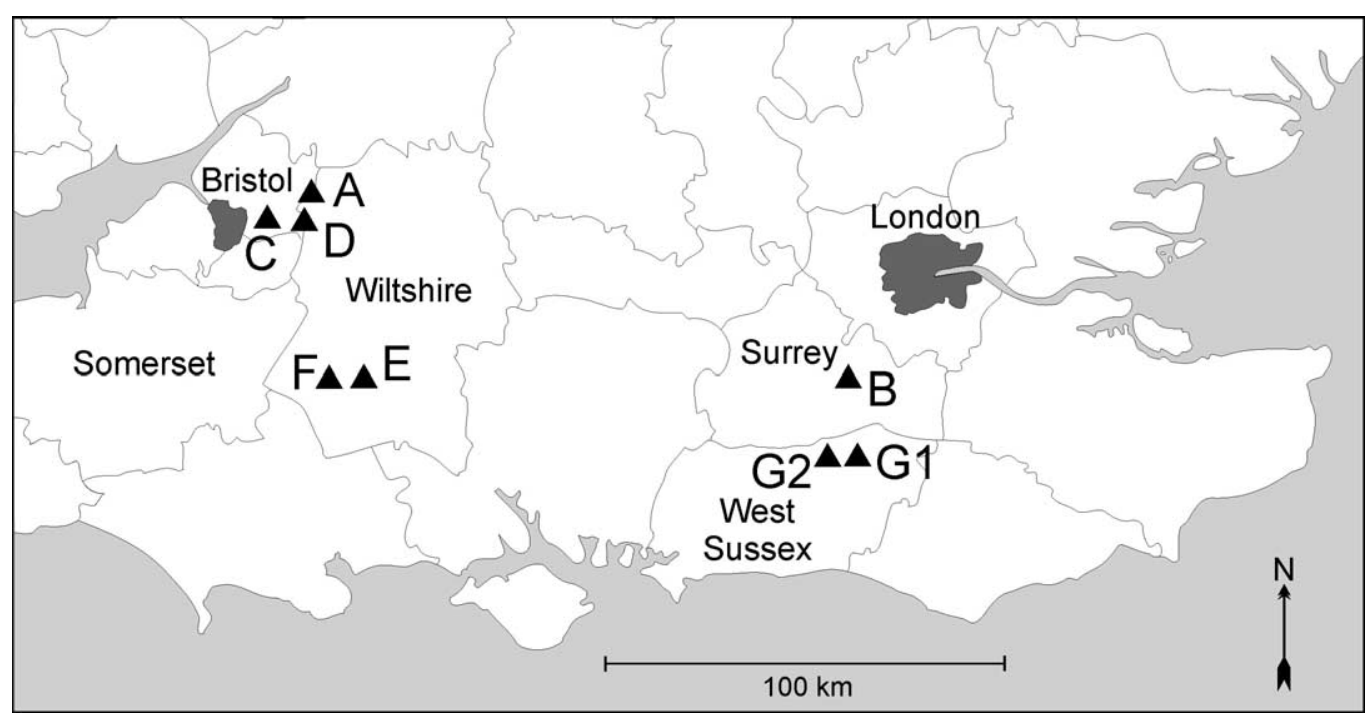

Fig. 1. Location of study sites in southern England. (A) Box limestone mine, (B) Westhumble chalk mine, (C) Combe Down limestone mine, (D) Farleigh limestone mine, (E) Chilmark stone mine, (F) Fonthill Grottos man-made caves, (G1) Cocking disused railway tunnel, and (G2) Drover's disused railway tunnel.

according to the degree of ossification of the epiphyseal joints in the finger bones (Racey, 1974; Anthony, 1988). Separation of juvenile from adult individuals was problematic during the autumn and became more difficult as the season progressed because the joints became increasingly fused (Thomas et al., 1979). Sexual maturity was investigated by observing nipples on females and testis size and epididymis colouration on males (Thomas et al., 1979; Racey, 1982, 1988). M. nattereri and M. daubentonii were ringed with $2.9 \mathrm{~mm}$ aluminium bat rings at site A from 1999. B. barbastellus were ringed at site B.

\section{Results}

\subsection{Species composition}

A total of 3077 bats from 11 of Britain's 16 bat species was caught (Table 1). In addition one Pipistrellus nathusii was caught at Site G. Captures at six of the seven sites were dominated by $M$. nattereri and $M$. daubentonii, comprising 36.5 and $31.6 \%$ of the total respectively. M. mystacinus, $M$. brandtii and M. bechsteinii contributed a large proportion of the remainder, the latter especially at sites $\mathrm{E}$ and $\mathrm{F}$ where $M$. bechsteinii comprised $>10 \%$ of the total. Both Rhinolophus species, E. serotinus, B. barbastellus and Pipistrellus spp. were found in small numbers overall, with the exception of site $\mathrm{C}$ where almost $10 \%$ of the total comprised $R$. ferrumequinum and $23 \%$ of the total comprised R. hipposideros.

Enough data were available at three sites to provide information about change in species composition during the course of the swarming season (Fig. 2). Temporal segregation was evident between the peak activity of
M. daubentonii and $M$. nattereri, especially at sites A and B. In all years, as the season progressed increasingly large numbers of $M$. nattereri and fewer $M$. daubentonii were caught. Catching began earlier in 2000 at sites A and $\mathrm{C}$ than in previous years, revealing a peak in $M$. brandtii before that of $M$. daubentonii. Species richness was generally highest during the first half of the swarming season. Trends were consistent across all years.

\subsection{Sex and age composition}

Sex ratio was consistently highly male-biased across all sites for Myotis spp., B. barbastellus, E. serotinus and $P$. auritus (Table 1). G-tests tested for deviations from a sex ratio of unity for species where sample size was $>10$. In 27 of 32 tests performed on species data from the study sites, the observed sex ratio was found to be significantly different from unity and in all cases a male bias was evident. Five results were not significantly different from unity, two $R$. ferrumequinum, two $R$. hipposideros and one $M$. nattereri. None was female biased.

Age composition was stable over time with on average $78 \%$ adults among captured bats. Detailed analysis was done for site A only, where there was greater confidence in the ageing of bats and a large sample size was collected with a good temporal distribution during the swarming season. Over a period of 14 catch dates in 1999 and $2000,60 \%$ of the bats caught were adult males. Adult females comprised 19\%, juvenile males $14 \%$ and juvenile females only $7 \%$.

\subsection{Additional catches and hibernation counts}

Spring and early summer catches revealed lower species richness and lower activity than during the swarming 


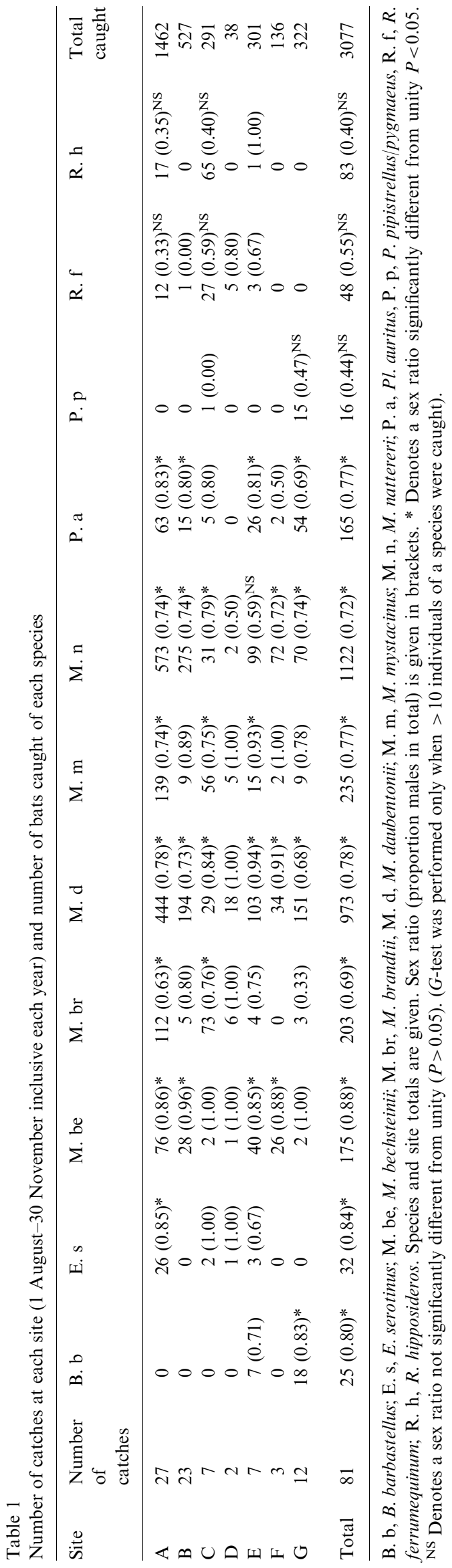

season though fewer catches were carried out during these times. At site $G$, for example, three catches in April and May together resulted in 18 bats of only four species. Similarly, at site A, a catch in March, possibly involving bats caught on emergence from hibernation in the mine, resulted in only 29 bats of four species, $62 \%$ of which were $M$. nattereri. Two catches in May and one in July resulted in only five bats altogether. Two catches in May at site C consisted only of $R$. ferrumequinum and $R$. hipposideros and no other species.

Hibernation counts were carried out three times a year at site A between 1997 and 2000. On average, 18 M. nattereri, 30 M. mystacinus/M. brandtii, $11 M$ daubentonii and less than five $P$. auritus were counted per year. Several hundred $R$. hipposideros and $R$. ferrumequinum and hibernate at this site. In December 2000 and February 2001 three ringed $M$. nattereri (two male, one female) and one ringed male $M$. daubentonii were found hibernating in the mine close to the entrance at which they were caught in August and September 2000. Similarly, hibernation counts at site $G$ have been very consistent in consecutive years. On average 205 bats are recorded per counting event. $M$. nattereri comprise half of those seen, $M$. daubentonii between a quarter and a third and the remainder were M. mystacinus and M. brandtii.

\section{Discussion}

It is evident from this study that swarming occurs among several species of Microchiroptera resident in Britain. As has been suggested from studies in North America and in continental Europe (Davis and Hitchcock, 1965; Hall and Brenner, 1968; Fenton, 1969; Schowalter, 1980; Bauerova and Zima, 1988; Degn et al., 1995; Kugelschafter, 1995; Lubczyk and Nagel, 1995) the dominant species participating in this activity are of the genus Myotis. Swarming in Britain appears particularly prevalent among $M$. nattereri and $M$. daubentonii, but this could in part reflect their relative abundance compared with the other Myotis species (Harris et al., 1995). More M. bechsteinii were caught than would have been expected from previous records and estimated abundance (Hutson, 1993; Harris et al., 1995). The area in which some or all of the study sites are located may be particularly rich for that species. The apparent abundance of certain species could in part be due to the distribution of catches during the swarming season. For example, because of the temporal segregation between $M$. daubentonii and $M$. nattereri, a greater amount of catching later in the season would result in a larger proportion of $M$. nattereri being caught. Due to unavoidable variation in catching effort between sites (number of catches, number of years surveyed, number of hours spent trapping and the number of traps used) a 


\section{Site A}

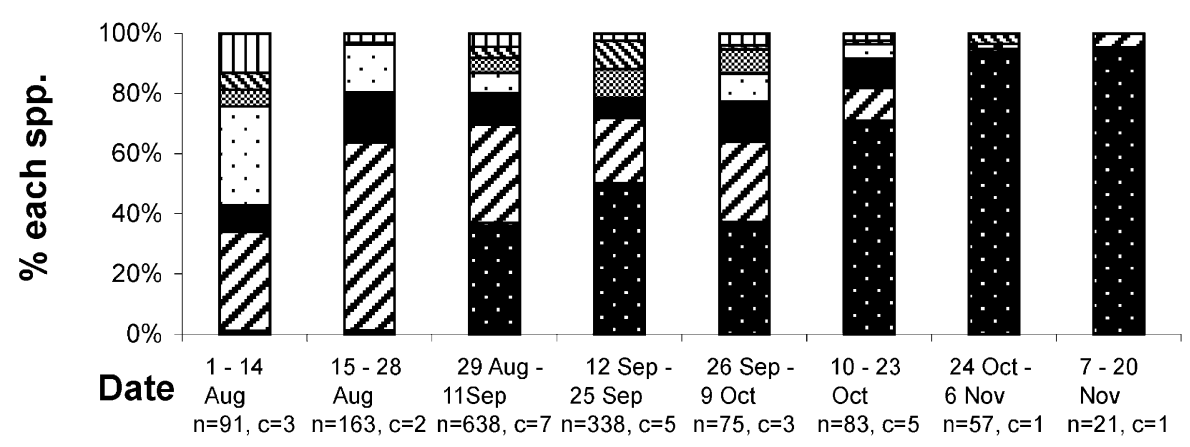

Site B

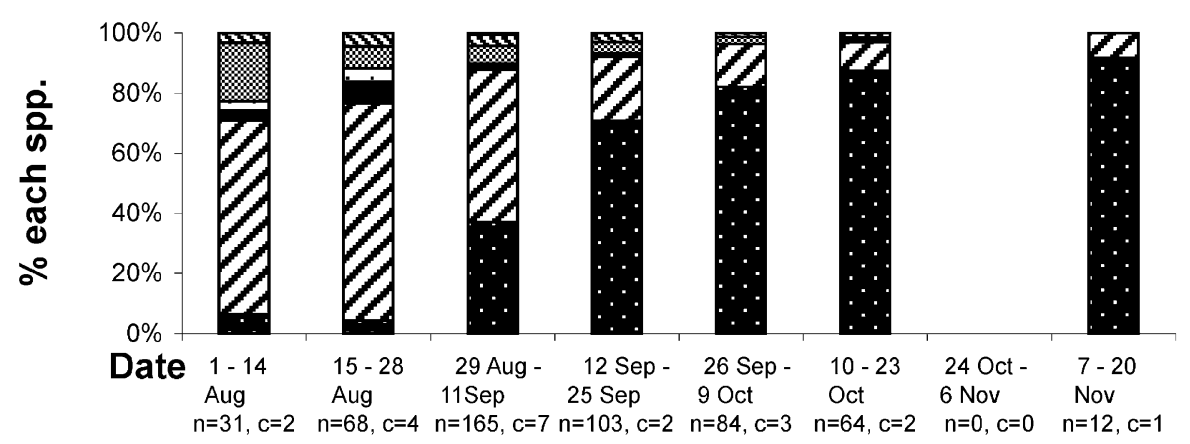

\section{Site C}

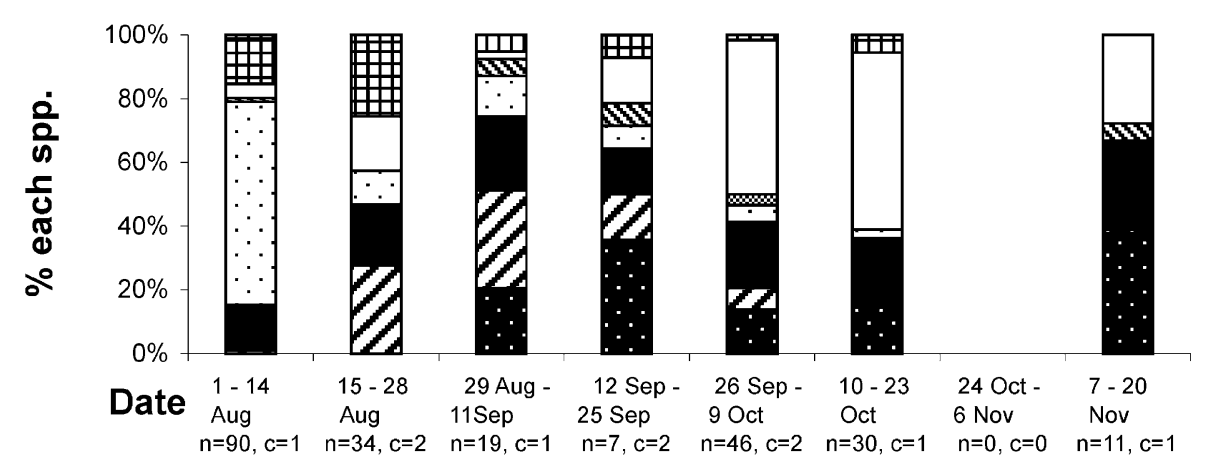

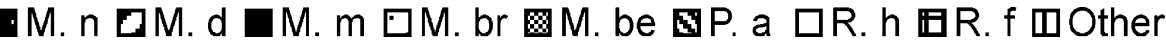

Fig. 2. Change in species composition with time between 1 August and 20 November for three sites. For sites A and B data from several years were pooled into fortnightly blocks and average proportions calculated from the catching events within each fortnightly block. For site $\mathrm{C}$ data were from year 2000 only. Beneath the x-axis in parentheses is (the number of bats in the sample, followed by the number of catching events used to compile the sample). For legend abbreviations see Table 1. Category 'Other' contains E. serotinus, P. auritus and Pipistrellus spp.

direct comparison between the sites in terms of numbers of individuals and the number of different species caught is not possible and is not necessary for the purpose of this paper. Also, the natural fluctuation in level of swarming activity throughout the swarming season renders comparisons of numbers of bats caught between nights and across sites invalid. We therefore restrict our analysis to species found at each site, temporal variation within sites, and investigation of sex ratios.

$P$. auritus and B. barbastellus are present at some sites during the swarming season. Frequent capture of $B$. barbastellus during the summer and high recapture rates of marked individuals suggest that this species has regular night-roosts at underground sites throughout 
the year and they are known to use one tunnel as a flight path. Hence they may not swarm to the degree shown by Myotis bats. Similarly captures of E. serotinus may be attributed to night-roosting activity between feeding bouts. The fact that not all species swarm suggests that it must constitute an adaptive behaviour, such as a mating system exhibited by only some species. It should be noted that there might be some trapping-bias due to some species being better able to detect and avoid traps and nets than others. Preliminary investigations have shown that the two Rhinolophus species may be better at detecting and avoiding traps than the Myotis due to their higher echolocation frequency and greater manoeuvrability.

The peak swarming activity was found to be between mid-August and mid-September. Catches during this time resulted in the greatest number of captured bats Temporal progression in the dominance of $M$. daubentonii to $M$. nattereri through the season is consistent with that found by other researchers (Bilo et al., 1989; Harrje, 1994; Lubczyk and Nagel, 1995; Trappmann, 1997). However, the peak in M. brandtii before that of $M$. daubentonii has not previously been referenced. The order of peak swarming activity is an exact reverse of the pattern seen on departure from hibernation, whereby $M$. nattereri depart earliest followed by $M$. daubentonii and $M$. brandtii are the last to leave (Degn, 1987). This is probably reflective of the availability of prey and foraging mechanisms of the bats. For example $M$. nattereri is a gleaning species and may be better able to locate prey later or earlier in the year than an aerial hawking species (Barclay, 1991).

The strong male bias found at all sites for the Myotis species may be because males are more nomadic and visit swarming sites more often than females during the swarming season while females are more faithful to a home range before requiring an underground hibernaculum during harsh weather. We would therefore expect greater recapture rates for males than for females. From preliminary observations this seems to be the case (between 1999 and 2001 at site A recaptures of M. nattereri have been $100 \%$ male and of $M$. daubentonii $88 \%$ male). Recapture of marked bats during swarming was greater between years than within the same year

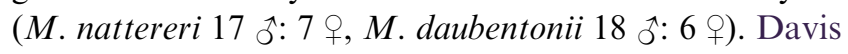
and Hitchcock (1965) found that sex ratio in M. lucifugus was highly male biased in late July and August and gradually approached unity with time until an equal number of males and females were found during hibernation between November and March. There was no clear decrease in male bias towards unity in our study and too few are seen in hibernation to calculate sex ratios at that time.

Both species of Rhinolophus had sex ratios near to unity at sites $\mathrm{A}$ and $\mathrm{C}$ where sufficient numbers of these species were caught for statistical analysis. At these sites $R$. ferrumequinum are known to have breeding colonies and both species are seen frequently hibernating in the sites. These are the only species to roost consistently underground at the sites and this could explain the equal sex ratio. Rhinolophus are not thought to 'swarm' but rather, during the autumn, males occupy territories for a period of days/weeks during which time females visit and select a male for mating (Ransome, 1990).

During the course of captures at a swarming site the changing stages of sexual readiness from spermatogenesis through to sperm storage in the epididymis are clearly seen in the sexually mature males which form the core of the captured population. That this behaviour occurs at the time of peak sexual condition supports the idea that there is a connection with mating as suggested by previous authors (Fenton, 1969; Humphrey and Cope, 1976; Thomas et al., 1979).

Catching during the spring and early summer months demonstrated a low usage of the sites at these times. More individuals were caught when emerging from hibernation than during May and July but it was not possible to conclude that swarming occurred in March and April (as suggested by Humphrey and Cope, 1976; Bauerova and Zima, 1988; Harrje, 1994). Underground sites are traditionally surveyed for hibernating bats between December and February. In south-west Britain the majority of bats found hibernating in such sites are horseshoe bats, which hang from the walls and ceilings, whereas Myotis species tend to hibernate out of sight (Stebbings, 1988) (a possible exception are tunnel sites where the availability of cracks and crevices is less than in caves or mines and so bats of all species are more visible). Hence, in general, Myotis species are under-represented during hibernation counts of sites in south-west Britain.

Bats do not exclusively hibernate at the sites at which they swarm (Hall and Brenner, 1968; Trappmann, 1997). Some, for example, M. bechsteinii are very rarely, if ever, found hibernating in underground sites (Trappmann, 1997; authors personal observation) and marked individuals of $M$. nattereri have been found hibernating in alternative underground sites during the winter (Trappmann, 1997).

Some individuals, particularly $M$. brandtii and juveniles of $M$. daubentonii were caught on emergence from underground sites during the swarming season with rock-dust and dirt on their fur. We take this as evidence that these species day-roost in the underground sites during the swarming season, but rock dust could also be picked up during mating on the rock surface. The dayroosting activity is likely to be transitory but nevertheless is of conservation importance.

\section{Conservation implications}

The implications of the findings of this study to the conservation of all bat species found at swarming sites 
are considerable. Surveys at swarming sites have revealed far more species and individuals than would otherwise be recorded. Underground sites have been known to be important for British bat species for many years as refuges for breeding and hibernation. Such sites appear to have equal or perhaps greater importance during late summer and autumn as sites for swarming and for night roosting for a large variety of bat species including, in Britain, all five resident species of Myotis, Plecotus auritus, B. barbastellus and E. serotinus. The UK population of $M$. nattereri may be of international importance (Stebbings, 1988; Hutson, 1993; MacDonald and Tattersall, 2001) and this species was found frequently at all sites together with $M$. daubentonii. This survey indicates that $M$. bechsteinii and B. barbastellus, species that are considered rare at a national level (Hutson, 1993; MacDonald and Tattersall, 2001), may focus at underground sites from large areas and hence protection of such sites is vital. These species may be more numerous than previously thought. Sites of particular use at certain times of year by these vulnerable species such as swarming sites must be given special protection.

Bat detector surveys and hibernation counts alone are not adequate to assay the numbers of species and individuals present in an area or at a particular hibernation site, particularly for species with low population density. Consequently the conservation importance of such areas or sites may be grossly underestimated. Swarming season surveys of underground sites should be included in population monitoring in an area to give a more complete picture of species richness and hence the importance of sites with respect to planning by conservation authorities. Due to the high number of species and individuals at swarming sites criteria should be developed for selecting Sites of Special Scientific Interest (SSSI). In the UK the majority of bat SSSI sites are designated for roosting bats, hence swarming [in which the majority of bats are not (permanently) resident at the site] adds a new dimension to bat conservation. That some of the sites are important hibernacula for $R$. ferrumequinum and $R$. hipposideros, and in some cases also nursery sites bodes well for their protection, but the high activity at such sites between August and October must be taken into account in conservation planning. As a direct result of swarming studies two of the sites in this study have been designated as candidate Special Areas of Conservation (cSAC) for B. barbastellus and $M$. bechsteinii. Catching is an invasive technique and should be used only when absolutely necessary. The development of non-intrusive, automated multi-species monitoring systems with consistent recording protocols should be a priority.

Underground sites are important centres of activity on evenings in late summer and autumn, and conservation is especially important if the sites are confirmed to be important centres for mating activity as suspected.
There may be a limited number of suitable sites in a region, and if site fidelity is high then site loss would have important consequences for the survival of local and perhaps regional populations. Outbreeding has been linked with the promotion of survival in bats (Rossiter et al., 2001). The fact that bats are travelling great distances (maximum recorded $40 \mathrm{~km}$ in this study) to reach swarming sites also has implications, such as the maintenance of adequate corridors for commuting and the provision of suitable roosting and foraging habitat around swarming sites.

Consideration must be given to swarming activity when giving permission for caving activities during late summer and autumn, which frequently take place in the evening after dark. Observations have shown that most activity during swarming occurs in and around the entrances to underground sites, hence the design and placing of grilles may be of importance in the continued use of such sites by bats.

\section{Acknowledgements}

We are grateful to members of the lab in Bristol, undergraduate students and local bat groups for their help on catch nights. Tony Hutson of Sussex Bat Group kindly supplied hibernation data for Cocking and Drover's Tunnels. Thanks to site owners for permission to access their land for the purposes of this study. Colin O' Donnell provided valuable comments on earlier drafts of this manuscript.

\section{References}

Anthony, E.L.P., 1988. Age determination in bats. In: Kunz, T.H (Ed.), Ecological and Behavioural Methods for the Study of Bats. Smithsonian Institute Press, Washington DC, pp. 47-58.

Barbour, R.W., Davis, W.H., 1969. Bats of America. University Press of America, Lexington.

Barclay, R.M.R., 1991. Population structure of temperate zone insectivorous bats in relation to foraging behaviour and energy demand. Journal of Animal Ecology 60, 165-178.

Bauerova, Z., Zima, J., 1988. Seasonal changes in visits to a cave by bats. Folia Zoologica 37, 97-111.

Bilo, M., Harbusch, C., Weishaar, M., 1989. Sommerliche Fledermausaktivitaton an Hollen und Stollen. Dendrocopus 16, 17-26.

Clutton-Brock, T.H., Harvey, P.H., 1978. Mammals, resources and reproductive strategies. Nature 273, 191-195.

Cross, S.P., 1965. Roosting habits of Pipistrellus hesperus. Journal of Mammalogy 46, 270-279.

Davis, W.H., 1964. Fall Swarming at (sic) bats at Dixon Cave, Kentucky. The National Speleological Society Bulletin 26, 82-83.

Davis, W.H., Hitchcock, H.B., 1965. Biology and migration of the bat Myotis lucifugus in New England. Journal of Mammalogy 46, 296-313.

Degn, H.J., 1987. Bat counts in Mønsted Limestone cave during the year. Myotis 25, 85-90.

Degn, H.J., Andersen, B.B., Baagøe, H, 1995. Automatic registration of bat activity through the year at Mønsted Limestone Mine, Denmark. Zeitschrift für Säugetierkunde 60, 129-135. 
Fenton, M.B., 1969. Summer activity of Myotis lucifugus (Chiroptera: Vespertilionidae) at hibernacula in Ontario and Quebec. Canadian Journal of Zoology 47, 597-602.

Hall, J.S., Brenner, F.J., 1968. Summer netting of bats at a cave in Pennsylvania. Journal of Mammalogy 49, 779-781.

Harris, S., Morris, P., Wray, S., Yalden, D., 1995. A review of British mammals: population estimates and conservation status of British mammals other than cetaceans. JNCC, Peterborough.

Harrje, C., 1994. Etho-okologische Untersuchung der ganzjahrigen Aktivitat von Wasserfledermausen (Myotis daubentonii Kuhl, 1819) am Winterquartier. Mitteilungen der Naturforschenden Gesellschaft Schaffhausen 39, 15-52.

Humphrey, S.R., Cope, J.B., 1976. Population Ecology of the Little Brown Bat, Myotis lucifugus, in Indiana and North-central Kentucky. Special Publication of the American Society of Mammalogists, Oklahoma.

Hutson, A.M., 1993. Action Plan for the Conservation of Bats in the United Kingdom. The Bat Conservation Trust, London.

Hutson, A.M., Mickleburgh, S.P., Racey, P.A., 2001. Microchiropteran Bats: Global Status Survey and Conservation Action Plan. IUCN/SSC Chiroptera Specialist Group. IUCN, Gland, Switzerland and Cambridge, UK.

Kretzschmar, F., Heinz, B., 1995. Social behaviour and hibernation of a large population of Pipistrellus pipistrellus (Schreber, 1774) (Chiroptera:Vespertilionidae) and some other bat species in the mining system of a limestone quarry near Heidelberg (South West Germany). Myotis 32-33, 221-229.

Kugelschafter, K., 1995. Vergleichende Untersuchungen zur Nutzung der Segeberger Kalkberghohle und deren Umgebung durch Wasser- und Fransenfledermause-Konsequenzen fur ein effectives Schutzkonzept. In: Arbeitskreis Wildbiologie, Justus-LeibigUniversitat.

Lubczyk, P., Nagel, A., 1995. Aktivitat von Fledermausen an einem Winterquartier im Landkreis Luchow-Dannenberg (Niedersachsen, BRD) im Winterhaldjahr 1993/1994. Der Ornithologische Beobachter 92, 339-344.

MacDonald, D.W., Tattersall, F., 2001. Britain's Mammals: The Challenge for Conservation. People's Trust for Endangered Species, London.

O'Shea, T., 1980. Roosting, social organization and the annual cycle in a Kenya population of the bat, Pipistrellus nanus. Zeitschrift fur Tierpsychologie 53, 171-195.

Racey, P.A., 1974. Ageing and assessment of reproductive status of pipistrelle bats, Pipistrellus pipistrellus. Journal of Zoology, London 173, 264-271.

Racey, P.A., 1982. Ecology of reproduction. In: Kunz, T.H. (Ed.), Ecology of Bats. Plenum Press, New York, pp. 57-104.

Racey, P.A., 1988. Reproductive assessment of bats. In: Kunz, T.H. (Ed.), Ecological and Behavioural Methods for the Study of Bats. Smithsonian Institute Press, Washington DC, pp. 31-45.

Racey, P.A., Entwistle, A.C., 2000. Life-history and reproductive strategies of bats. In: Crichton, E.G., Krutzch, P.H. (Eds.), Reproductive Biology of Bats. Academic Press, London, pp. 363-414.

Ransome, R.D., 1990. The Natural History of Hibernating Bats. Christopher Helm, Kent.

Rossiter, S.J., Jones, G., Ransome, R.D., Barratt, E.M., 2001. Outbreeding increases offspring survival in wild greater horseshoe bats (Rhinolophus ferrumequinum). Proceedings of the Royal Society, London (B) 268, 1055-1061.

Schowalter, D.B., 1980. Swarming, reproduction and early hibernation of Myotis lucifugus and Myotis volans in Alberta, Canada. Journal of Mammalogy 61, 350-354.

Shiel, C.B., Fairley, J.S., 2000. Observations at two nursery roosts of Leisler's bat Nyctalus leisleri (Kuhl, 1817) in Ireland. Myotis 37, 4153.

Stebbings, R.E., 1988. Conservation of European Bats. Christopher Helm, London.

Thomas, D.W., Fenton, M.B., Barclay, R.M.R., 1979. Social behaviour of the Little Brown Bat, Myotis lucifugus. I. Mating behaviour. Behavioural Ecology and Sociobiology 6, 129-136.

Trappman, C., 1997. Aktivitätsmuster einheimischer Fledermäuse an einem bedeutenden Winterquartier in der Baumbergen. Abhandlungen aus dem Westfälischen Museum für Naturkunde 59, 5162.

Whitaker, J.O., Rissler, L.J., 1992. Winter activity of bats at a mine entrance in Vermillion County, Indiana, 1992. American Midland Naturalist 127, 52-59.

Whitaker, J.O., 1998. Life history and roost switching in six summer colonies of Eastern Pipistrelles in buildings. Journal of Mammalogy $79,651-659$. 